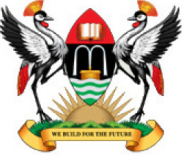

East African School of Higher Education Studies \& Development
Makerere Journal of Higher Education

ISSN: 1816-6822; 4(2) (2013) $221-234$

DOI: http://dx.doi.org/10.4314/majohe.v4i2.7

(C) The Author(s) 2013

Reprints \& permission: EASHESD

http://ajol.info/majohe

\title{
Development of a Nigerian Business Law Module for Business Students at the University of Hull, United Kingdom
}

\author{
Eghosa Osa Ekhator ${ }^{1}$ \\ ${ }^{1}$ Law School, University of Hull [E-mail: e.o.ekhator@2005.hull.ac.uk]
}

\begin{abstract}
This paper will focus on the development of a business law centred module. Here, the module will be 'Introduction to Business Law in Nigeria' for part time business administration students in an English university. These cohorts of students are business owners undergoing a part time programme in business administration who are interested in investing in the Nigerian economy via the medium of foreign direct investment. The development of this module will highlight the extant business laws and regulations in Nigeria and it will be of immense help to the various business owners on the course. The learning and teaching approach to be used in this module will be integrated, encompassing the benefits of tutor and student centred approaches.
\end{abstract}

Keywords: Business Law, Course Design, SOLO Taxonomy.

\section{$1 \quad$ Introduction}

This paper will be divided into five sections. The first section will focus on the development of a module in the UK university system. The second section of the paper will dwell on the approaches to student learning. Here, deep and surface learning approaches will be in focus. The third part of the paper will dwell on the inherent limitations in the module development process. The fourth section will focus on the development of a 'Business Law' module for part time students in an English University. This is the crux of the paper and relevant theories will be used in the development of the module. In the fifth section, conclusions are drawn. A major finding of the paper is that the recent increases in tuition paid by university students in England has led to increased expectations on universities to deliver world class education in England. This is especially relevant in developing new modules in universities in the UK. 


\section{Developing Academic Modules}

Developing any academic module is not an easy task. This is especially so, if the module developer is a new lecturer or not versed in module development nous. However, a major advantage of being a teacher in a university or higher citadel of learning is that teachers in universities have control of the curriculum (Toohey 1999). Susan Toohey emphasizes this notion by stating that much of the creativity and power in teaching lies in the design of the curriculum: the choice of texts and ideas which become the focus of study, the planning of experiences and the means by which achievement is assessed (Toohey 1999:1). Thus, the university teacher exemplifies the totality of the academic experience in that particular module. Here, a healthy teacher-student relationship is achieved by the instrumentality of a good course or module design (Toohey 1999).

The development of a module entails various diverse and sometimes an integrated process. The whole gamut of developing a module is encapsulated in the basic map of module development as posited by Jennifer Moon (Moon 2002). She states that the development of a module entails level descriptors, aims, learning outcomes, assessment criteria, assessment methods and teaching strategy (Moon 2002: 16-17). The various stages in module development are critical to the success of any module. The level descriptors in the basic map of a module development entails what a student is expected to achieve at the end of the study or module. Learning outcomes entail statements of what a learner is expected to know, understand or be able to do at the end of the module and of how that learning will be demonstrated (Moon 2002: 17). An assessment criterion is the statement that evidences the standard of a performance a student is supposed to attain at the end of the module. Assessment methods are the task that is undertaken by the learner that is the subject of assessment (Moon 2002: 17). Lastly, in the basic map of module development as enunciated by Moon, a teaching strategy involves the totality of support available and given to learners to enable them in actualising the learning outcomes. The various levers in the basic map if properly developed and aligned will lead to students engaging in deep learning. A good module should encourage this kind of learning.

Similarly, Diamond (1989) in Toohey (1999: 21) enunciates a model of a course design process. Herein, a typical course design process entails six stages. The stages are: 1. Establish the need and demand for a course or module. 2. Establish student criteria or characteristics 3. Determine the type of content in the module or course 4. Set goals, aims and objectives 5.Choose teaching and assessment methods and finally implement, evaluate and adjust components as necessary. Diamond's classification of the module development process is 
similar to that of Toohey. Thus, attaining deep learning via the instrumentality of the course or module development process is at the core of both models.

However, in developing the Nigerian Business Law module, this paper is guided by the assertions of Nordberg (2008: 82) wherein he posited that "teaching will need to be interactive and it is precisely here where issues of coherence may arise in modular course design especially when, for fiscal reasons, it may not make business sense to develop many new modules when there remains capacity to include more students in existing teaching sessions".

\section{$3 \quad$ Approaches to Student Learning}

There are two major approaches to student learning. These two approaches are deep and surface learning (Biggs, 1999; Allen, 2008; Ramsden, 1992; Toohey, 1999; Entwhistle, 1981). According to Marton and Saljo (1976) in Toohey (1999), the first academics to investigate student's approach to learning were in Sweden. In the course of their research, Marton and Saljo asked a group of students to read some academic papers and describe the process of what they learnt and how they actualised it. The outcome of the research was that the students used different approaches or methods in the learning process and these approaches came to be known as either deep or surface learning.

Furthermore, during this period Biggs (1979) and (Entwistle and Ramsden 1983) among other researchers in the United Kingdom were also investigating the ways students engaged in learning processes (Toohey 1999). These researchers used factor analysis of student's responses to questionnaires on their study intentions and behaviour. The results were very similar to those of the Swedish researchers.

Deep learning occurs when students aim at achieving a thorough understanding of a module. Learners engage deeply and thoroughly with the module. They adopt strategies such as reading widely and discussing with others and make sense of new knowledge in terms of what they already know (Toohey 1999: 9). Also, deep learners relate ideas to previous knowledge, thereby checking evidence and relating it to its conclusions (Entwistle, 2009; Atherton, 2011). Deep learners don't aim at achieving high grades; their major aim is having a thorough understanding of the module is the major aim. Notwithstanding, deep learners are said to perform better than surface learners in assessments (Allen 2008). They tend to study all of the topics in a module in which they are expected to be examined or assessed, predict test questions and plan their study time (Toohey, 1999). Also, deep learners can be termed 'strategic learners' who tend to obtain higher grades by engaging in competition with their peers. Also, strategic learners endeavour to achieve high 
grades enjoy being academically challenged, through achieving their ambitions (Moon, 1999).

Surface learners are students who do not see the need to go beyond what is necessary for them to pass their examinations. They make no effort to achieve a thorough or in-depth understanding of the topics in their modules. Their strategy is to reproduce enough of the information they have been given to satisfy the assessment criteria (Toohey, 1999: 10). Surface learning is a disincentive to students thus, surface approaches.....cannot occur in an ideal learning environment (Ramsden 1992: 45)). However, not all students engaging in surface learning are aiming at merely passing examinations. Some also aim at achieving high scores or grades in their modules. These students' high scores can be achieved through rehashing more information in examinations or assessments. Here, this form of surface learning is termed 'Achieving' or strategic approach, which can be summarised as a very well-organised form of surface approach, and in which the motivation is to get good marks (Atherton 2011). Thus, the exercise of learning is construed as a game, so that acquisition of technique improves performance and it works as well as the analogy: in so far as learning is not a game, it breaks down (Atherton 2011).

According to Gibbs (1992 in Toohey, 1999) and Biggs (1995 in Toohey, 1999), factors that could encourage surface learning by students include -

1. Time stress resulting from heavy workload, high module or class contact hours, large volume of module materials and emphasis on coverage of the module.

2. An assessment process which encourages low level outcomes, rewards learners for engaging or recalling few strands of relevant information and leads to undue stress or anxiety

3. Lack of choice over topics, subjects and methods or ways of study

4. A classroom and departmental atmosphere which encourages negativity and cynicism.

Furthermore, Hamm, Tafe and Robertson (2010: 953) are in support of the above views on surface learning. They contend inter alia:

1. Time and effort: surface learners tend to do just enough to complete the assessment. They spend only the time required to meet the minimum requirements.

2. Questions asked: surface learners ask how rather why.

3. Level of research: they use the information provided.

4. Impact of assessment: surface learners focus on assessable tasks only.

5. Cognitive effort: surface learners aim at memorisation and rote taking.

6. Importance of personal interest: surface learners spend a greater amount of time on topics of personal interest" 
On the other hand, factors encouraging deep learning include an appropriate motivational context, a high degree of learner activity, interaction with others (both peers and teachers) and a well-structured knowledge base. These factors were reflected in a research conducted by Brenda Clare (2007) which focused on the different stages of operationalising deep learning among student-social workers.

In developing a Business Law module, this paper will take cognisance of the factors that encourage deep learning and encapsulate them in the totality of the development.

At the core of any educational theory is the notion that individuals are not inherently deep or surface learners, but that effective teaching encourages deep learning. Thus, any teaching methods used must be geared towards the promotion of deep learning (Allen, 2008: 182). This view posited by Allen is analogous to the constructive alignment discourse exemplified by the works of Biggs (1999, 2003, and 2007 among others). Biggs argues that an alignment between the learning outcomes of a module, the teaching and learning process and assessment are paramount. Constructive alignment entails the notion that a learner constructs his or her own learning through relevant learning activities (Biggs, 2003: 1). The role of a teacher is to create an environment that encourages learning activities that will actualise the desired learning outcomes (Biggs, 2003). A poor learning system exists wherein the components (of teaching or learning) are not integrated, and are not tuned to support high-level learning (Biggs, 2003: 1) akin to the surface learning approach. Some students will find this as a major disincentive in their study. On the other hand, in a good (constructive alignment) learning system the aim is to achieve a curriculum design that encourages conditions for quality learning akin to a deep learning approach with the ultimate aim of helping students to achieve a thorough understanding of a module.

\section{Limitations on Module Development}

The higher education sector in the United Kingdom has undergone tremendous changes in the last thirty years. Twenty years ago, public funding of the Universities was the norm in the UK (Biggs and Tang, 2007). Public funding of universities in the UK is being reduced by the government. Presently, in the UK, income from student-fees accounts for about $29 \%$ of universities total funding (BBC 2011). Also, about 35\% of the funding of universities comes from government funding bodies or agencies such as endowments, research grants and investments (BBC 2011). However, in England, the funding of universities is going to be skewed towards the student from September 2012. 
Thus, from September 2012, universities in England are raising tuition fees (for home students) to up to $£ 9,000$ per year due to the major shortfalls in budgetary allocations to universities (BBC 2011).

The rise in student fees has led to profound (negative) effects on teaching and learning of students in universities in the UK (Biggs and Tang, 2007). However, government still contends that a highly educated workforce will assist in economic growth or competiveness (Knight and Yorke, 2003). Due to increased tuition fees to be paid by students in the UK, students will demand better services and teaching by universities and enhanced job prospects (Biggs and Tang, 2007). Thus, there may be pressure on university teachers to teach in a more student-friendly environment which may lead to lowering of academic standards (Biggs and Tang, 2007).

Universities in the UK face budgetary cuts and this is a major disincentive in investing in course development by universities (Nordberg 2008). In order to improve its revenue or finances, some universities prefer to invest in projects (such as consultancy and externally funded research institutes) or courses that will generate extra income (Nordberg 2008). Here, many universities in the UK attract thousands of international students to courses such as Masters in Business Administration (MBA) and other business modules. One way of making a Nigerian Business Law module attractive to universities in the UK, is by marketing the strengths of the module to Multinational Companies operating in Nigeria and imploring the companies to invest in its development, for example, by granting scholarships or grants to interested and qualified applicants. Thus, the Multinational Companies can invest in a Nigerian Business Law module in the UK as part of its Corporate Social Responsibility (CSR) activities and this will attract many students to study the module.

Furthermore, tremendous pressure to teach more students for longer hours, reduce costs and increase income have been barriers on effective teaching (Toohey, 1999). However, there are very good examples of course design appearing which apply much of the recent research into learning in creative ways (Toohey, 1999: 1). A major theme of curriculum or module development is the broadening of the higher education curriculum. This process involves designing courses which foster engagement with the subject matter and reward deep learning (Toohey, 1999: 2). Notwithstanding the difficulties in the UK university system, good module development is one way of adding value to the quality of the UK university system. Qualitative and efficient development of modules will attract students from other countries to come and study in the UK. If more international students are attracted to UK universities, the funding cuts imposed by the government may be cushioned with funding from the fees paid by the international students.

Some of the common problems of course design in universities in the present times include (e.g. difficulties in integrating theory and practice) are long 
standing but many reflect recent changes in the nature of tertiary education which have considerable impact on the design of subjects and courses (Toohey, 1999). In developing a module for the purposes of this paper, the common problems inherent in module development will be avoided.

\section{Development of a Nigerian Business Law Module}

In the development of a module, the most important question is what is most important for these students to know and what might be the best ways for them to learn it? (Toohey, 1999: 25). This question is at the core of this paper. In trying to answer the question, Biggs (2003)'s four stages in the constructive alignment paradigm will be in focus. The stages are:

1. Defining the intended learning outcomes (ILOs).

2. Choosing teaching/learning activities likely to lead to the ILOs,

3. Assessing students' learning outcomes to see how well they match what was intended

4. Arriving at a final grade.

Other relevant considerations in course development are: determining the framework and who should be involved in the framework (Toohey, 1999: 2633). In respect of the module in focus, the relevant considerations are what type of skills are the students bringing into the programme, what is the assessment criteria, how will the teaching and learning be delivered. Will technology play a major role in learning and assessment process? Also, will there be any disabled students on the programme? In answering these aforementioned questions, an effective module that encompasses deep learning will be achieved.

The law module for part time business is a new module that is being created to cater for individuals or representatives of companies that are interested in investing in the Nigerian economy. Many of the expected students are busy individuals who manage or run businesses and companies. The major Intended Learning Objective of the programme is to make available to the students the extant Nigerian law on business. This module is a first year module. In analysing the construction of the module, factors such as learning outcomes, assessment, learning and teaching approaches and the use of technology will be in focus.

\subsection{Learning Outcomes of the Module}

Biggs and Tang defines an intended learning outcome (ILO) as a statement describing what and how a student is expected to learn after exposure to teaching(2007: 65). There are three levels of outcome statement and these are 
institutional, degree programme level and course level (Biggs and Tang, 2007). This paper is concerned with the course level. Furthermore, in teaching any module, teachers should have a clear notion of what the students are supposed to learn (Biggs 2003). Here, topics should be made concise and clear to the students. Biggs (2003) distinguishes between 'declarative' and 'functioning' knowledge. Declarative knowledge is the knowledge that learners espouse to people orally or in writing. However, learners need to utilise and make knowledge function (Biggs 2003). Intended learning outcomes in any module should be geared towards the attainment of functional knowledge by students at the end of their programmes. Thus, deep learners always engage in the attainment of functional knowledge in learning.

In analysing student understanding of learning outcomes, some theories are very relevant. The SOLO taxonomy which was first propounded by Biggs and Collis (1982) can be used to analyse learning outcomes. Thus, the SOLO taxonomy is one method of measuring the impacts of the learning process on the students or learners. SOLO is an acronym for the structure of the observed learning outcome (Biggs and Collis, 1982). The value of the SOLO taxonomy is encapsulated in the following statement by Biggs and Tang (2007:76).

It provides a systematic way of describing how a leaner's performance grows in complexity when mastering many academic tasks. It can be used to define course ILOs, which describe where students should be operating and for evaluating learning outcomes so that we can know at what level individual students are actually operating.

The SOLO taxonomy consists of five levels that describe the structures of the represented Learning (Moon, 1999:124). They include inter alia:

"(a) Pre-structural - there is no appropriate structure to the task;

(b)Unistructural - only one general element is represented;

(c) Multicultural - more than one general element is present in the representation, but they are poorly integrated in a serial or unrelated manner;

(d)Relational - here there are relevant elements present and they are integrated in a coherent and interdependent manner; development of any appropriate new structure is competent but not generalized to new situations;

(e) Extended abstract - the coherent structure is developed into an effective and coherent new structure in a competent manner, from which there are generalizations to new situations."

The SOLO taxonomy has been applied in a plethora of learning approaches in diverse disciplines. However, a major weakness inherent in the SOLO taxonomy is that it does not take cognisance of the differences in representation caused by the actual content of the material (Moon 1999). The SOLO taxonomy excludes some concerns that might have negative effects on the learning process. For example, the structure of a response may be determined 
by the nature of the task such as examination question to be achieved rather the competence of the learner (Dahlgren, 1997; Moon, 1999). Also, in respect of international students, culture and personal problems might have a negative impact in their learning process.

During the course of student learning, two major changes in learning occur. These are quantitative and qualitative changes. Quantitative change occurs when the amount of study or response to details by a student increases and qualitative changes occurs when the detail is well integrated in the totality of the learning experience of the student (Biggs and Tang 2007). The quantitative stage in learning is akin to the surface approach and qualitative is analogous to deep approach in learning. Learning outcomes should encourage qualitative changes in the learning structure of students.

Another theory that can be used to analyse or assess student learning is Bloom's taxonomy (1965). Here, Bloom's taxonomy “provides a quick check on what levels of cognitive skills might be demanded by an assessment task. It should be noted that at each succeeding level assumes competence at an earlier stage" (Brown et al, 1997: 36). Tutors should encourage deep learning in learners because they (learners) will make deeper meanings of what you are teaching by making connections to the existing concepts invariably helping them to remember the materials. Here, teachers should encourage deep learning wherein learners try to focus on the meaning of the text; they proceed to the higher level of the Bloom's Cognitive Taxonomy, application, analysis, synthesis, evaluation and generativity (Shen, 2006: 43). Thus, learners should be encouraged by teachers to engage in a participatory view of knowledge wherein the learners are responsible for their learning by relating what they have learnt with their interpersonal, intrapersonal and social contextual domains, the learners become intrinsically motivated (Shen 2006). This leads to deep learning by learners engaging in the participatory view of knowledge and such learners operate at the higher rungs of the Bloom's taxonomy wherein they can apply and modify the knowledge learnt.

On the other hand, learners who engage in surface learning are said to be operating within the 'spectator view of knowledge' (Shen 2006). Here, learners are not motivated and rarely make meaning of what they have learnt and do not construct knowledge. The spectator view of knowledge is the traditional learning process which leads to the superficial engagement of texts or materials by learners and thus, learners under the spectator view of knowledge are likely to stay in the lower rungs of the Bloom's taxonomy and end up with a superficial mastery of the knowledge (Shen 2006). However, surface learning is not inherently a negative in the learning process. Learners on the lower rungs of the Blooms Taxonomy (such as comprehension and knowledge) are said to be surface learners. In the author's view, surface learning is better than 'no learning' by students. 
In developing law modules in UK universities recourse is made to The Quality Assurance Agency for Higher Education benchmark for law. Here, it provides a basis for institutions to devise their own learning outcomes compatible with the benchmark standards (QAA 2007). Also, the benchmark provides guidance on wordings of learning outcomes and other considerations inherent in law modules. Furthermore, the University of Hull Learning Outcomes Tool is a very helpful framework in developing learning outcomes in modules at the University of Hull. The aim of the University of Hull Learning Tool is to help staff clarify the learning outcomes they write for their programmes. The aim is to help staff design robust learning outcomes and clarify to students what is expected of them at different stages of their programme of study (University of Hull Learning Tool, 2007: 5).

In writing learning outcomes, some verbs are usually used. Here, generic high level and low level verbs are usually used (Biggs 2003). Some examples of generic high level verbs include, reflect, solve, hypothesis amongst others (Biggs 2003). Examples of low level verbs include identify, describe and memorise amongst others (Biggs 2003). Verbs used in learning outcomes reflect the levels of the students and levels of understanding. Thus, first year students learning outcomes will contain low level verbs. On the other hand, masters or final year students learning outcomes will contain generic high level verbs. The reason is that final year and post graduate students are deemed to have a higher level of understanding compared to first year students.

This law module being developed is for first year part time business administration students. Thus, the learning outcomes herein will contain low level verbs because the students are not law students and they are first year.

\subsection{Learning and Teaching Approach of the Module}

The module being developed will be delivered using the mixed methods entailing aspects of tutor and student learning approaches. Examples of tutor centred methods include lectures, seminars, e-learning, tutorials and workshops. Examples of student centred methods include experiential learning, action learning and inquiry based learning. In law modules, there are some unique teaching and learning methods. These include lecture-textbook (lecture method of teaching), case study, Socratic Method, problem method and research method among others (Danov 2011). This module will use a mixture of lecturetextbook and seminar methods for delivering lectures and learning. This method is chosen because it will encourage appropriate learning activities in the module. This will also promote deep learning approach in students. 


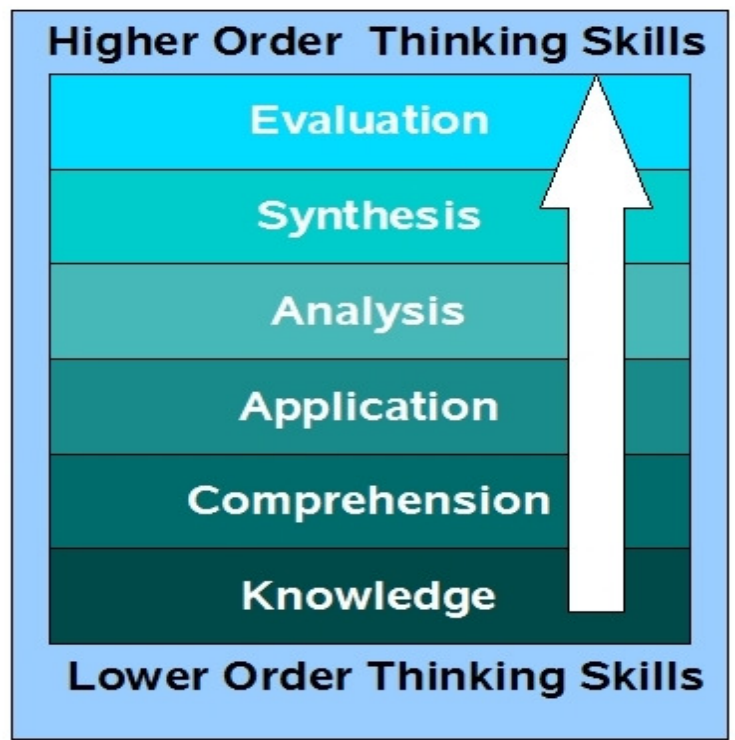

Figure 1: Bloom's Taxonomy Source: The University of Hull (2012)

\section{Module Rationale}

Business Law in Nigeria is a very important part of Nigerian jurisprudence. Business law deals with a very wide area in Law. Some of the topics in this module constitute a course each in law and attract a separate textbook. This module will serve as an introduction to the various themes in Nigerian business law. The module will give students the opportunity to engage in the literature on Nigerian business law.

\section{Learning Outcomes}

At the end of the module, the learners will be able to:

1. Identify and outline fundamental and limited concepts of Nigerian Business Law.

2. Demonstrate general awareness of the various themes underpinning Nigerian Business law.

3. Demonstrate some ability to draw on or refer to the prescribed literature/information sources.

4. Demonstrate the ability to recall and recognize the inter-relationships amongst the various topics in the module.

\section{Learning and Teaching Strategies}

The following learning and teaching strategies are used within this module:

Intellectual and transferable/professional skills will be strengthened through interactive seminars, class presentations, group assignments, and essay writing.

\section{Assessment Strategies}

The following assessment strategies are used within this module:

- $\quad$ One 3,000 word essay

Reassessment will take the same form as the initial assessment for this module. 


\section{Arrangements for Revision and Private Study}

Students will be provided with comprehensive reading lists that will allow them to undertake independent research based on guidance from the tutor. Students spend a maximum of six hours a week in the classroom providing substantial time for study outside the classroom. Students will have at least a three week period from the end of the teaching session to prepare their assessments for submission. Under normal circumstances there will be no class in Week 12 of the semester. Access to the tutor will be via email or e-bridge.

\section{Module Constraints}

No pre/post-requisite requirements have been recorded for this module.

\section{Indicative Content}

A - An introduction to Law of Contract

B - The history and development of the Law of Agency in Nigeria

C - The scope of Nigerian Company Law

D - The law of sale of Goods

E - The Law of Partnership

F - The Law of Negotiable Instruments in Nigeria

$\mathrm{G}$ - Investment laws in Nigeria

\section{Staffing}

To be announced later

\section{Recommended Reading}

Ekhator.E. O. and Okumagba, E. 'A Critical Analysis of Veil Lifting in the United Kingdom'. Forthcoming in the Delsu Law Review July 2013.

Oshio, E, (1994) Modern Business Law in Nigeria. Department of Business law, University of Benin; Benin City.

Sanni, A (2000) Introduction to Nigerian Business Law in Nigeria. Malthouse Publishing; Nigeria.

\section{Conclusion}

Module development is a tedious task for any lecturer. The aim of any module is to engage students in deep learning approaches. This paper has undertaken a preview of module development in the UK. The paper has applied theoretical views to the development of a law module for business students in UK universities.

\section{References}

Allen, G. (2008). The use of multiple choice questions as a form of formative assessment on an undergraduate law module". Law Teacher, 42(2), 180-199. 
Atherton, J.S (2011). Learning and Teaching; Deep and Surface learning. $\begin{array}{llll}\text { Retrieved } & 4 & \text { June }\end{array}$ from http://www.learningandteaching.info/learning/deepsurf.htm

BBC Website (2011). Q\&A: Tuition Fees. Retrieved 4 June 2013 from http://www.bbc.co.uk/news/education-11483638 last accessed 15/06/2012.

Bloom, B.S. (1956). Taxonomy of Educational Objectives. Handbook 1: Cognitive Domain. London: Longman.

Biggs, J, B. (2003). Aligning for Constructive Learning. Retrieved 4 June 2013 from http://www.heacademy.ac.uk/assets/documents/resources/database/id477_ali gning_teaching_for_constructing_learning.pdf

Biggs, J.B (1989). Approaches to enhancement of tertiary teaching. Higher Education Research and Development, 8, 7-25.

Biggs, J.B. (1999). What the Student Does: Teaching for Quality Learning in Universities. Buckingham: SRHE and Open University Press.

Biggs, J.B. (1995) Student Approaches to Learning, constructivism, and student centred learning, in Twentieth International Conference on Improving University Teaching. University of Maryland; University College.

Biggs, J.B and Collis, K.F. (1982) Evaluating the Quality of Learning: The SOLO Taxonomy. New York: Academic Press

Biggs, J. and Tang, K., (2007). Teaching for quality learning at University : what the student does" ( $3^{\text {rd }}$ edn). McGraw-Hill/Society for Research into Higher Education \& Open University Press: Maidenhead.

Brown, G. et al (1997). Assessing Student Leaning in Higher Education. Routledge: Oxford.

Clare, B. (2007). Promoting Deep Learning: A Teaching, Learning and

Assessment Endeavour, Social Work Education: The International Journal, 26(5), 433-446.

Diamond, R.M (1989) Designing and Improving Courses and Curricula in Higher Education. San Francisco: Jossey-Bass.

Dahlgren, L. (1997). Learning conceptions and outcomes. In The Experience of Learning, eds Marton, F, Hounsell, D and Enwistle, N. Scottish Academic Press, Edinburgh.

Danov, M. (2011). Teaching international commercial arbitration at postgraduate level - techniques for enhancing students' learning, The Law Teacher, 45:1, 101-113.

Ekhator, E.O. (2009). Regulation of Labour Standards: An International Perspective. Journal of Globalisation and Development in Africa 2(June), 11-28.

Enwistle, N.J. (1981). Styles of Learning and Teaching. New York: John Wiley and Sons. 
Entwistle, N.J. \& Ramsden, P. (1983). Understanding Student Learning. London: Croom Helm.

Entwistle, N.J (2009). Teaching for Understanding at University: Deep Approaches and Distinctive Ways of Thinking. Basingstoke : Palgrave Macmillan

Gibbs, G. (1992) Improving the quality of student learning through course design, in Barnett, (Ed). Learning to Effect. Buckingham: SRHE and Open University.

Hamm, S, Tafe, W.A \& Robertson, I. (2010). Preferences for deep-surface learning: A vocational education case study using a multimedia assessment activity. Australian Journal of Educational Technology 26(7), 951-965.

Knight, P.T. and Yorke, M. (2003) Assessment, Learning and Employability. Society for Research into Higher Education \& Open University Press: Maidenhead.

Moon, J. (1999). Reflection in Learning and Professional Development: Theory and Practice. Abingdon: Routledge/ Falmer.

Moon, J. (2002). The Module and Programme Development Handbook: A Practical Guide to Linking Levels, Outcomes and Assessment Criteria. London: Routledge/Farmer.

Marton, F. And Saljo, R. (1976). On qualitative differences in learning: IOutcomes and process. British Journal of Educational Psychology, 46:4-11.

Nordberg, D. (2008) Designing business curricula: building relevance into higher education. International Journal of Management Education, 7 (1), 8186.

The Quality Assurance Agency for Higher Education benchmark for law (2007). Retrieved 4 June 2013 from https://www.qaa.ac.uk/academicinfrastructure/benchmark/statements/Law07. pdf

Ramsden, P. (1992). Learning to Teach in Higher Education. (First Edition) Routledge: London.

Shen, D. (2006). The Enablers and Barriers of Providing Profession Practical Skills Education to the Rural Elementary School Students in Zhejiang, China. (Doctoral dissertation). Retrieved from Google Books.

Toohey, S. (1999). Designing Courses for Higher Education. SRHE \& Open University Press: Buckingham.

University of Hull Quality Learning Outcomes Tool (2007). Retrieved 4 June 2013

from http://www2.hull.ac.uk/administration/pdf/quality_LearningOutcomesTool.p df.

University of Hull (2012). Teaching, supporting and assessing student learning $\begin{array}{lllll}\text { module handouts. } & \text { Retrieved } 4 & \text { June } & 2013\end{array}$ from https://ebridge.hull.ac.uk/portal. 